\title{
BMJ Open Cross-sectional association between body fat percentage and arteriosclerosis assessed by Cardio-Ankle Vascular Index in a Chinese population: a retrospective observational study
}

\author{
Linfeng He, ${ }^{1}$ Lijuan Bai, ${ }^{1}$ Lihua Liu, ${ }^{1}$ Yun Liu, ${ }^{1}$ Ruiyun Wang, ${ }^{1}$ Yaoling Wang, ${ }^{1}$ \\ Man Liao, ${ }^{1}$ Yizhou Wan, ${ }^{2}$ Benling Qi (i) ${ }^{1}$
}

To cite: He L, Bai L, Liu L, et al. Cross-sectional association between body fat percentage and arteriosclerosis assessed by Cardio-Ankle Vascular Index in a Chinese population: a retrospective observational study. BMJ Open 2022;12:e056281. doi:10.1136/ bmjopen-2021-056281

- Prepublication history for this paper is available online. To view these files, please visit the journal online (http://dx.doi. org/10.1136/bmjopen-2021 056281).

LH and LB contributed equally.

Received 10 August 2021 Accepted 24 December 2021

Check for updates

(c) Author(s) (or their employer(s)) 2022. Re-use permitted under CC BY-NC. No commercial re-use. See rights and permissions. Published by BMJ.

${ }^{1}$ Department of Geriatrics, Union Hospital, Tongji Medical College, Huazhong University of Science and Technology, Wuhan, Hubei, China

${ }^{2}$ Department of Orthopaedics, Union Hospital, Tongji Medical College, Huazhong University of Science and Technology, Wuhan, Hubei, China

Correspondence to

Benling Qi;

qibenlingok_2015@163.com

\section{ABSTRACT}

Objective To evaluate arteriosclerosis using Cardio-Ankle Vascular Index (CAVI) and to explore the relation between the body fat percentage (BFP) and CAVI.

Design A retrospective observational study.

Setting and participants $A$ total of 1152 patients

admitted to a geriatric unit and general practice at a mega hospital in Wuhan, China, from November 2018 to November 2019 were included in this study.

Primary outcome Association between BFP and CAVI. Results Multiple linear regression analysis showed that BFP was positively correlated with CAVI after correction for potential confounding variables $(\beta=0.03 ; 95 \% \mathrm{Cl}$ : 0.01 to 0.05 ); this association persisted after BFP was treated by quartile categorical variables and the trend test was statistically significant ( $p$ for trend=0.002). Meanwhile, the generalised additive model showed a non-linear association between BFP and CAVI. When BFP $<20.6 \%$, BFP is not associated with CAVI for $(\beta=-0.02 ; 95 \% \mathrm{Cl}$ : -0.06 to 0.03 ), but when $\mathrm{BFP} \geq 20.6 \%$, there is a linear positive association between BFP and CAVI ( $\beta=0.05$; $95 \% \mathrm{Cl}: 0.02$ to 0.07$)$. Subgroup analysis showed that there was an interaction between BFP and CAVI in the age stratification ( $p$ interaction $=0.038$ ).

Conclusion BFP was non-linearly correlated with CAVI, with a 0.05 increase in CAVI for every $1 \%$ increase in BFP when $\mathrm{BFP} \geq 20.6 \%$ and a 0.03 increase in CAVI in those $>65$ years of age.

\section{INTRODUCTION}

Obesity and cardiovascular disease are two major threats to the world's public health. It was reported that in 2019, around 55.4 million people died worldwide and one-third of these deaths were due to cardiovascular disease, with the proportion in China even reaching over $47 \% .^{1}$ In addition, obesity is also prevalent worldwide, with the number of overweight and obese people increasing from 921 million in 1980 to 2.1 billion in $2013 .^{2} \mathrm{~A}$ 2015 study in China found that the number of overweight and obese people in the country

\section{Strengths and limitations of this study}

- We used a generalised linear model to clarify the true association between body fat percentage (BFP) and Cardio-Ankle Vascular Index (CAVI).

- Subgroup analysis reduces heterogeneity across populations.

- This study does not follow-up the population to observe the effect of changes in BFP on CAVI.

- We were unable to include confounding factors such as exercise, diet and lipid-lowering medication use for analysis due to the retrospective nature of the study.

reached a staggering 600 million. ${ }^{3}$ What are brought by obesity are cardiovascular diseases such as coronary heart disease (CHD), hypertension and heart failure, ${ }^{4}$ with over twothirds of obesity-related deaths resulting from cardiovascular disease. ${ }^{6}$ Obesity and cardiovascular diseases are closely linked, while the main bridge between the two is atherosclerosis $(\mathrm{AS})$. $^{7}$

Arteriosclerosis, as an atherosclerotic process, has been shown to be associated with obesity. Studies by Tang et $a l^{8}$ and Vianna $e t$ at ${ }^{9}$ showed that brachial-ankle pulse wave velocity (bapwv) increased with body mass index (BMI), but the opposite result was seen in studies by Rodrigues et $a l^{10}$ and Yang et $a .^{11}$ Clearly, this falls into the so-called obesity paradox, ${ }^{12} 13$ making the relationship between obesity and arteriosclerosis controversial. In contrast to previous studies, we speculate that this controversy may be due to the fact that BMI does not reflect the true picture of adiposity and the vulnerability of bapwv to blood pressure. ${ }^{14}$ Therefore, this study uses body fat percentage (BFP), which is a more accurate assessment of obesity, and 
Cardio-Ankle Vascular Index (CAVI), which is more accurate than bapwv and is independent of blood pressure for analyses. ${ }^{1516}$ In this study, we explored the relationship between BFP and CAVI and analysed other factors that may influence CAVI as well.

\section{PARTICIPANTS AND METHODS Study participants}

A retrospective collection of 1152 patients who met the following two conditions at the same time: (a) those who were admitted to our geriatrics and general medicine departments from November 2018 to November 2019 and (b) those who had both arterial elastance and BFP measurements. Patients who met the following criteria were excluded: (1) unable to provide BFP and CAVI; (2) acute infection; (3) acute myocardial infarction; (4) stroke; (5) heart failure; (6) Cushing's syndrome; (7) primary aldosteronism; (8) nephrotic syndrome; (9) malignancy and (10) hormone therapy.

\section{Study methods}

Clinical characteristics and blood indicators

Information including age, gender, history of tobacco or alcohol consumption, diuretic use and comorbidities including hypertension, CHD, peripheral artery disease (PAD, defined as imaging tests such as Doppler ultrasound suggesting AS formation in the peripheral arteries and a discharge diagnosis of peripheral AS), diabetes, osteoporosis, chronic kidney disease (CKD), chronic obstructive pulmonary disease (COPD) and fatty liver at the time of hospitalisation were obtained from the hospital electronic medical record system. Blood indices such as total cholesterol (TC), triglycerides (TG), high-density lipoprotein cholesterol (HDL-C), low-density lipoprotein cholesterol (LDL-C) and fasting glucose were collected by an automated biochemical analyzer from patients after 8 hours of fasting.

\section{Measurements of BFP and CAVI}

Subjects rested quietly in the supine position for about 5 min with hands placed flat on both sides of the body; cuffs were placed upper side of the elbow joints of both upper arms and both ankle joints; heart sound sensors were placed at the second intercostal sternum and ECG electrodes were placed at both wrists. All parts were checked to be connected properly, which took about $5 \mathrm{~min}$. The CAVI values of the right and left sides of the subjects were measured using the VS-1500 arterial elastometer from Fukuda, Japan, and the mean values of the CAVI values on both sides were included in the study. The height, weight, BMI and BFP of the examinees 2 hours after meal were measured using Tsinghua Tongfang BCA-2A bioelectrical impedance body composition analyzer. The above-related operations were performed by professionals.

\section{Statistical analysis}

First, comparisons were made between BFP quartile groups, with continuous variables expressed as mean \pm SD or median $(\mathrm{Q} 1-\mathrm{Q} 3)$ and categorical variables as $\mathrm{n}(\%)$. One-way ANOVA, Kruskal-Wallis and $\chi^{2}$ tests were employed to elaborate the differences between these groups. Second, univariate linear regression was adopted to analyse the relationship between variables and CAVI. Third, BFP was included in the linear regression as a continuous variable and categorical variable to make clear the relationship between BFP and CAVI. Nonadjusted model, adjust I model and adjust II model were also constructed in the case of uncorrected variables and corrected variables, respectively. Besides, trend test was conducted to illustrate the group differences with BFP as a categorical variable. Fourth, the generalised additive model (GAM) was used to fit the curve of BFP and CAVI. Fifth, the two-segment linear regression model was used to calculate the best inflection point of the fitted curve. Finally, subgroups were made to observe the relationship between BFP and CAVI in different populations and their interactions were referenced to figure out the differences between such populations. A two-sided $p$ value less than 0.05 was statistically significant. All statistical analyses were performed using R V.3.6.3.

\section{Patient and public involvement}

Patients and/or the public were not involved in the design, or conduct, or reporting, or dissemination plans of this research.

\section{RESULTS \\ Baseline characteristics}

A total of 1152 people participated in this study, ranging from 18 to 95 years, of whom 798 were male, accounting for $69.3 \%$. According to results, age, BMI, BFP, systolic blood pressure (SBP), HDL-C, TG, fasting glucose, gender, the prevalence of hypertension, diabetes, osteoporosis and fatty liver were statistically different among BFP quartile groups. So was the number of smokers and drinker. Compared with other three groups, participants in the Q4 group had higher age, BMI, BFP, SBP, fasting glucose, female proportion and fatty liver prevalence, and this group had fewer smokers and drinkers. More details are shown in table 1 .

\section{Relationship between age, BMI and BFP}

Spearman correlation analysis showed that age $(r=0.200$, $\mathrm{p}<0.001)$ and BMI $(\mathrm{r}=0.410, \mathrm{p}<0.001)$ were positively correlated with BFP (figure 1). In figure 1A, locally estimated scatterplot smoothing showed that age was negatively correlated with BFP in people older than 70 years. Figure $1 \mathrm{~B}$ shows that, in contrast to the situation when BMI $>22$, a rapid increase was observed in BFP when $\mathrm{BMI}<22$.

\section{Univariate linear regression}

According to univariate linear regression, age, gender, SBP, fasting glucose and the prevalence of hypertension, diabetes, $\mathrm{PAD}$, CHD, osteoporosis, $\mathrm{CKD}$, and COPD were 
Table 1 Baseline characteristics

\begin{tabular}{|c|c|c|c|c|c|}
\hline BFP & Q1 & Q2 & Q3 & Q4 & $P$ value \\
\hline $\mathrm{N}$ & 277 & 296 & 289 & 290 & \\
\hline Age (years, mean $\pm S D$ ) & $54.80 \pm 14.47$ & $56.46 \pm 13.60$ & $58.46 \pm 13.86$ & $61.66 \pm 13.65$ & $<0.001$ \\
\hline $\mathrm{BMI}\left(\mathrm{kg} / \mathrm{m}^{2}\right.$, mean $\left.\pm \mathrm{SD}\right)$ & $22.12 \pm 2.59$ & $24.38 \pm 2.61$ & $25.16 \pm 3.12$ & $26.05 \pm 3.70$ & $<0.001$ \\
\hline $\mathrm{BFP}(\%$, mean $\pm \mathrm{SD})$ & $18.83 \pm 3.80$ & $24.01 \pm 0.97$ & $27.26 \pm 1.10$ & $33.27 \pm 3.16$ & $<0.001$ \\
\hline $\mathrm{SBP}(\mathrm{mm} \mathrm{Hg}$, mean $\pm \mathrm{SD})$ & $125.09 \pm 15.75$ & $128.98 \pm 16.54$ & $130.16 \pm 17.48$ & $134.37 \pm 18.98$ & $<0.001$ \\
\hline $\mathrm{DBP}(\mathrm{mm} \mathrm{Hg}, \mathrm{mean} \pm \mathrm{SD})$ & $81.13 \pm 10.33$ & $83.54 \pm 10.80$ & $82.45 \pm 10.20$ & $81.73 \pm 10.84$ & 0.040 \\
\hline $\mathrm{TC}(\mathrm{mmol} / \mathrm{L}$, mean $\pm \mathrm{SD})$ & $4.32 \pm 1.08$ & $4.39 \pm 1.05$ & $4.47 \pm 1.12$ & $4.45 \pm 1.14$ & 0.355 \\
\hline $\mathrm{TG}(\mathrm{mmol} / \mathrm{L}$, median (Q1-Q3)) & $1.15(0.83-1.75)$ & $4.45(3.75-5.04)$ & $4.37(3.61-5.23)$ & $1.40(1.03-2.00)$ & $<0.001$ \\
\hline $\mathrm{HDL}-\mathrm{C}\left(\mathrm{mmol} / \mathrm{L}, \mathrm{mean}_{ \pm} \mathrm{SD}\right)$ & $1.25 \pm 0.36$ & $1.14 \pm 0.33$ & $1.17 \pm 0.34$ & $1.24 \pm 0.34$ & $<0.001$ \\
\hline LDL-C (mmol/L, median (Q1-Q3)) & $2.49(1.97-3.06)$ & $2.63(1.98-3.18)$ & $2.61(2.03-3.25)$ & $2.60(1.92-3.30)$ & 0.255 \\
\hline Fasting glucose (mmol/L, median (Q1-Q3)) & $4.83(4.49-5.36)$ & $4.94(4.61-5.60)$ & $5.00(4.57-5.62)$ & $5.13(4.69-5.73)$ & $<0.001$ \\
\hline $\mathrm{CHD}(\mathrm{n}, \%)$ & & & & & 0.842 \\
\hline No & $226(82.78 \%)$ & $230(80.42 \%)$ & $229(80.07 \%)$ & $231(80.49 \%)$ & \\
\hline Yes & $47(17.22 \%)$ & $56(19.58 \%)$ & $57(19.93 \%)$ & $56(19.51 \%)$ & \\
\hline Hypertension (n, \%) & & & & & $<0.001$ \\
\hline No & $154(56.41 \%)$ & $110(38.46 \%)$ & $116(40.42 \%)$ & $112(38.89 \%)$ & \\
\hline Yes & $119(43.59 \%)$ & $176(61.54 \%)$ & $171(59.58 \%)$ & $176(61.11 \%)$ & \\
\hline Diabetes (n, \%) & & & & & 0.001 \\
\hline No & $196(71.79 \%)$ & $175(60.55 \%)$ & $191(66.55 \%)$ & $164(56.94 \%)$ & \\
\hline Yes & $77(28.21 \%)$ & $114(39.45 \%)$ & $96(33.45 \%)$ & $124(43.06 \%)$ & \\
\hline $\operatorname{PAD}(n, \%)$ & & & & & 0.303 \\
\hline No & $265(97.07 \%)$ & $277(96.85 \%)$ & $277(96.85 \%)$ & $273(94.79 \%)$ & \\
\hline Yes & $8(2.93 \%)$ & $9(3.15 \%)$ & $9(3.15 \%)$ & $15(5.21 \%)$ & \\
\hline Osteoporosis (n, \%) & & & & & 0.042 \\
\hline No & $231(84.62 \%)$ & $250(87.41 \%)$ & 245 (85.66\%) & $228(79.17 \%)$ & \\
\hline Yes & $42(15.38 \%)$ & $36(12.59 \%)$ & $41(14.34 \%)$ & $60(20.83 \%)$ & \\
\hline Fatty liver (n, \%) & & & & & $<0.001$ \\
\hline No & $196(71.27 \%)$ & $164(56.36 \%)$ & $154(53.66 \%)$ & 139 (48.26\%) & \\
\hline Yes & $79(28.73 \%)$ & 127 (43.64\%) & 133 (46.34\%) & 149 (51.74\%) & \\
\hline Smoking (n, \%) & & & & & $<0.001$ \\
\hline No & $163(59.27 \%)$ & $172(59.11 \%)$ & $200(69.69 \%)$ & $251(87.15 \%)$ & \\
\hline Yes & $112(40.73 \%)$ & 119 (40.89\%) & 87 (30.31\%) & 37 (12.85\%) & \\
\hline Drinking (n, \%) & & & & & $<0.001$ \\
\hline No & 190 (69.09\%) & 175 (60.14\%) & 204 (71.08\%) & 255 (88.54\%) & \\
\hline Yes & $85(30.91 \%)$ & $116(39.86 \%)$ & $83(28.92 \%)$ & $33(11.46 \%)$ & \\
\hline Diuretic use (n, \%) & & & & & 0.388 \\
\hline No & $261(94.22 \%)$ & $271(91.55 \%)$ & $265(91.70 \%)$ & $262(90.34 \%)$ & \\
\hline Yes & $16(5.78 \%)$ & 25 (8.45\%) & $24(8.30 \%)$ & $28(9.66 \%)$ & \\
\hline
\end{tabular}

BFP, body fat percentage; BMI, body mass index; CAVI, Cardio-Ankle Vascular Index; CHD, coronary heart disease; CKD, chronic kidney disease; COPD, chronic obstructive pulmonary disease; DBP, diastolic blood pressure; HDL-C, high-density lipoprotein cholesterol; LDL-C, low-density lipoprotein cholesterol; PAD, peripheral artery disease; SBP, systolic blood pressure; TC, total cholesterol; TG, triglycerides. 

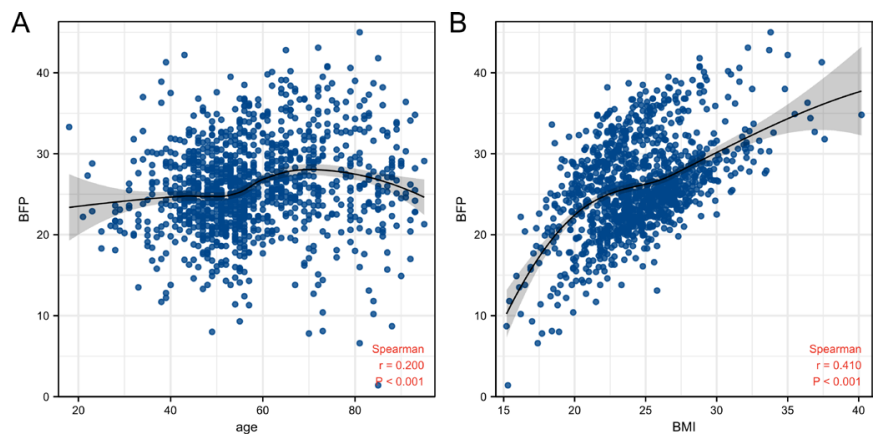

Figure 1 Scatterplot of age, BMI and BFP. (A) Age. (B) BMI. BFP, body fat percentage; BMI, body mass index.

positively correlated with CAVI; BMI, TC and TG were negatively correlated with CAVI and BFP, diastolic blood pressure (DBP), HDL-C, LDL-C and the prevalence of fatty liver, smoking and drinking were not correlated with CAVI. More details are shown in table 2.

\section{Different linear regression models}

The relationship between BFP and CAVI was elaborated by constructing the non-adjusted model, adjust I model and adjust II model. According to the non-adjusted model, BFP was not correlated with CAVI ( $\beta=0.00 ; 95 \%$ CI:-0.01 to 0.02 ). According to adjust I model where age, BMI and gender were corrected, BFP was positively correlated with CAVI ( $\beta=0.03 ; 95 \%$ CI:0.01 to 0.05 ), which was also true when BFP was employed as a categorical variable ( $p$ for trend=0.002). According to adjust II model, BFP was also positively correlated with CAVI. More details are shown in table 3.

\section{Generalised additive model}

The non-linear relationship between BFP and CAVI was observed using GAM (figure 2). BFP was not correlated with CAVI ( $\beta=-0.02 ; 95 \%$ CI: -0.06 to 0.03 ) on the left side of the inflection point $(<20.6)$ of the fitted curve. However, they were positively correlated $(\beta=0.05 ; 95 \%$ CI: 0.02 to 0.07 ) on the right side of the inflection point $(\geq 20.6)$. More details are shown in table 4 .

\section{Subgroup analysis}

The interaction among subgroups revealed that BFP had an interaction with age ( $p$ interaction $=0.011$ ). The interaction between BFP and CAVI was weaker in those $>65$ years $(\beta=0.03)$ than those $\leq 65$ years $(\beta=0.05)$. Such interaction was less significant in subgroups including gender, BMI, SBP, hypertension, diabetes, PAD, CHD, osteoporosis, CKD, COPD, fatty liver, smoking, drinking, DBP, TC, HDL-C, TG, fasting glucose and LDL-C (p interaction $>0.05)$. More details are shown in table 5 .

\section{DISCUSSION}

The relationship between BFP and CAVI was explored in this retrospective study on the Chinese population. We found a non-linear correlation between BFP and CAVI. At first, in a multiple linear regression analysis, our findings
Table 2 Univariate linear regression analysis

\begin{tabular}{lllr}
\hline & Statistics & $\boldsymbol{\beta}(\mathbf{9 5} \% \mathbf{C l})$ & P value \\
\hline $\begin{array}{l}\text { Age } \\
\text { Gender }\end{array}$ & $57.87 \pm 14.11$ & $0.06(0.06$ to 0.07$)$ & $<0.001$ \\
\hline \multicolumn{1}{c}{ Female } & $354(30.73 \%)$ & Reference & \\
\hline \multicolumn{1}{c}{ Male } & $798(69.27 \%)$ & $0.32(0.14$ to 0.50$)$ & $<0.001$ \\
\hline BMI & $24.46 \pm 3.36$ & $-0.06(-0.09$ to -0.04$)$ & $<0.001$ \\
\hline BFP & $25.91 \pm 5.80$ & $0.00(-0.01$ to 0.02$)$ & 0.612 \\
\hline SBP & $129.70 \pm 17.53$ & $0.02(0.02$ to 0.03$)$ & $<0.001$ \\
\hline DBP & $82.23 \pm 10.57$ & $0.01(-0.00$ to 0.02$)$ & 0.075 \\
\hline TC & $4.41 \pm 1.10$ & $-0.23(-0.31$ to -0.16$)$ & $<0.001$ \\
\hline TG & $1.84 \pm 1.76$ & $-0.07(-0.12$ to -0.02$)$ & 0.005 \\
\hline LDL-C & $2.82 \pm 6.30$ & $-0.01(-0.02$ to 0.01$)$ & 0.443 \\
\hline HDL-C & $1.20 \pm 0.35$ & $-0.22(-0.47$ to 0.02$)$ & 0.078 \\
\hline Fasting glucose & $5.46 \pm 2.19$ & $0.05(0.01$ to 0.09$)$ & 0.011 \\
\hline
\end{tabular}

Hypertension

\begin{tabular}{|c|c|c|c|}
\hline No & $492(43.39 \%)$ & Reference & \\
\hline Yes & $642(56.61 \%)$ & 0.70 (0.54 to 0.87 ) & $<0.001$ \\
\hline \multicolumn{4}{|c|}{ Diabetes } \\
\hline No & 726 (63.85\%) & Reference & \\
\hline Yes & $411(36.15 \%)$ & 0.66 (0.48 to 0.83$)$ & $<0.001$ \\
\hline \multicolumn{4}{|l|}{ PAD } \\
\hline No & 269 (23.76\%) & Reference & \\
\hline Yes & 863 (76.24\%) & 0.84 (0.64 to 1.03 ) & $<0.001$ \\
\hline \multicolumn{4}{|l|}{$\mathrm{CHD}$} \\
\hline No & $916(80.92 \%)$ & Reference & \\
\hline Yes & 216 (19.08\%) & 1.05 (0.84 to 1.25$)$ & $<0.001$ \\
\hline \multicolumn{4}{|c|}{ Osteoporosis } \\
\hline No & $954(84.20 \%)$ & Reference & \\
\hline Yes & 179 (15.80\%) & 0.56 (0.34 to 0.79$)$ & $<0.001$ \\
\hline \multicolumn{4}{|l|}{ CKD } \\
\hline No & 1066 (94.09\%) & Reference & \\
\hline Yes & $67(5.91 \%)$ & 1.09 (0.74 to 1.44$)$ & $<0.001$ \\
\hline \multicolumn{4}{|l|}{ COPD } \\
\hline No & $1092(96.38 \%)$ & Reference & \\
\hline Yes & $41(3.62 \%)$ & 1.18 (0.74 to 1.63 ) & $<0.001$ \\
\hline \multicolumn{4}{|c|}{ Fatty liver } \\
\hline No & 653 (57.23\%) & Reference & \\
\hline Yes & 488 (42.77\%) & $-0.15(-0.32$ to 0.02$)$ & $<0.001$ \\
\hline \multicolumn{4}{|c|}{ Smoking } \\
\hline No & $786(68.89 \%)$ & Reference & \\
\hline Yes & 355 (31.11\%) & $0.09(-0.09$ to 0.27$)$ & 0.347 \\
\hline \multicolumn{4}{|c|}{ Drinking } \\
\hline No & $824(72.22 \%)$ & Reference & \\
\hline Yes & $317(27.78 \%)$ & $-0.17(-0.36$ to 0.01$)$ & 0.068 \\
\hline
\end{tabular}

$\mathrm{BFP}$, body fat percentage; $\mathrm{BMI}$, body mass index; $\mathrm{CHD}$, coronary heart disease; $\mathrm{CKD}$ chronic kidney disease; COPD, chronic obstructive pulmonary disease; DBP, diastolic blood pressure; HDL-C, high-density lipoprotein cholesterol; LDL-C, low-density lipoprotein cholesterol; PAD, peripheral artery disease; SBP, systolic blood pressure; TC, total cholesterol; TG, triglycerides.

showed BFP was positively correlated with CAVI ( $\beta=0.03$; $\mathrm{p}=0.013$ ) even after correction of potential confounders. Such positive relationship persisted even after treating $\mathrm{BFP}$ as a quadratic categorical variable. However, the 
Table 3 Different linear regression models analysis between BFP and CAVI

\begin{tabular}{|c|c|c|c|}
\hline Exposure & $\begin{array}{l}\text { Non-adjusted } \\
(\beta, 95 \% \mathrm{Cl}, \mathrm{p})\end{array}$ & $\begin{array}{l}\text { Adjust I } \\
(\beta, 95 \% \mathrm{Cl}, \mathrm{p})\end{array}$ & $\begin{array}{l}\text { Adjust II } \\
(\beta, 95 \% \mathrm{Cl}, \mathrm{p})\end{array}$ \\
\hline BFP & $0.00(-0.01$ to $0.02,0.612)$ & $0.03(0.01$ to $0.05,0.011)$ & $0.03(0.00$ to $0.05,0.022)$ \\
\hline Q1 & Reference & Reference & Reference \\
\hline Q2 & $0.11(-0.13$ to $0.35,0.344)$ & $0.23(0.03$ to $0.42,0.024)$ & $0.20(0.00$ to $0.40,0.049)$ \\
\hline$P$ for trend & $0.07(-0.01$ to $0.14,0.081)$ & 0.15 (0.06 to $0.25,0.002)$ & $0.15(0.05$ to $0.25,0.002)$ \\
\hline
\end{tabular}

Non-adjusted model adjusts for: none.

Adjust I model adjusts for: age; gender and BMI.

Adjust II model adjusts for: age, gender, BMI, SBP, hypertension, diabetes, PAD, CHD, osteoporosis, CKD, COPD, fatty liver, smoking, drinking, DBP, TC, HDL-C, TG, fasting glucose, LDL-C and diuretic use.

BFP, body fat percentage; BMI, body mass index; CAVI, Cardio-Ankle Vascular Index; CHD, coronary heart disease; CKD, chronic kidney disease; COPD, chronic obstructive pulmonary disease; DBP, diastolic blood pressure; HDL-C, high-density lipoprotein cholesterol; LDL-C, low-density lipoprotein cholesterol; PAD, peripheral artery disease; SBP, systolic blood pressure; TC, total cholesterol; TG, triglycerides.

increase in the effect size $(\beta)$ between Q2 and Q3 subgroups was not significant, leading to the speculation that there was a non-linear relationship between BFP and CAVI, which could be clarified using GAM. The results showed a non-linear curve between BFP and CAVI after correcting confounding variables, with no correlation

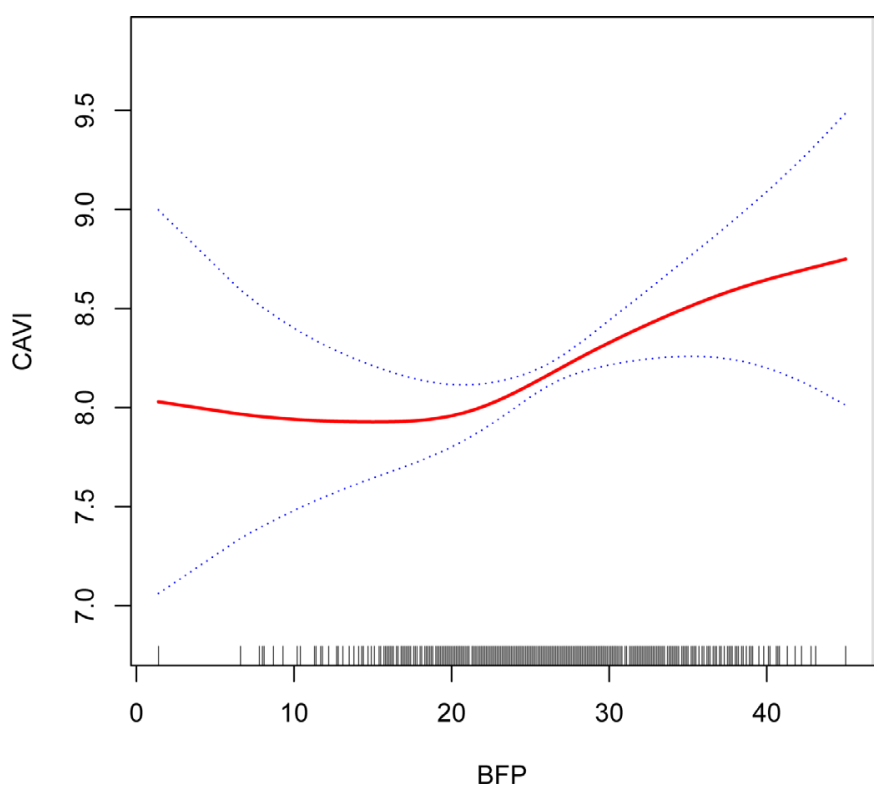

Figure 2 Fitting curve between BFP and CAVI. A nonlinear relationship between BFP and CAVI after adjusting for age, gender, BMI, SBP, hypertension, diabetes, PAD, CHD, osteoporosis, CKD, COPD, fatty liver, smoking, drinking, DBP, TC, HDL-C, TG, fasting glucose, LDL-C and diuretic use. BFP, body fat percentage; BMI, body mass index; CAVI, Cardio-Ankle Vascular Index; CHD, coronary heart disease; CKD, chronic kidney disease; COPD, chronic obstructive pulmonary disease; DBP, diastolic blood pressure; HDL-C, high-density lipoprotein cholesterol; LDL-C, low-density lipoprotein cholesterol; PAD, peripheral artery disease; SBP, systolic blood pressure; TC, total cholesterol; TG, triglycerides. between BFP and CAVI when $\mathrm{BFP}<20.6(\mathrm{p}=0.424)$, while a positive correlation when $\mathrm{BFP} \geq 20.6 \quad(\beta=0.05 ; \mathrm{p}=0.001)$. Subgroup analysis revealed a weaker interaction between BFP and CAVI among those $>65$ years compared with those $\leq 65$ years.

To clarify the correlation between BFP and CAVI, 'body fat percentage' and 'cardio-ankle vascular index' were searched as keywords on PubMed and only one report on BFP and CAVI was found. According to Czippelova et $a l,{ }^{17} \mathrm{BFP}$ was negatively correlated with CAVI among young obese people, but not statistically significant, which could be partly explained by its small sample (29 subjects) and uncorrected confounding variables. This study, which examined the correlation between BFP and CAVI, included more subjects (1152) and corrected potential confounding variables. Previous studies have proved the correlation between obesity and arteriosclerosis. ${ }^{18}{ }^{19}$ Studies by Tang $e t a l^{8}$ and Vianna $e t a l^{\ominus}$ demonstrated a positive correlation between BMI and baPWV, while studies by Rodrigues et $a l,{ }^{10}$ a Brazilian scholar, and Yang et $a l,{ }^{11}$ a Chinese scholar, advocated that BMI

\begin{tabular}{|c|c|c|c|}
\hline $\begin{array}{l}\text { Inflection point } \\
\text { of BFP }\end{array}$ & Effect size $(\beta)$ & $95 \% \mathrm{Cl}$ & $P$-value \\
\hline$<20.6$ & -0.02 & -0.06 to 0.03 & 0.424 \\
\hline$\geq 20.6$ & 0.05 & 0.02 to 0.07 & 0.001 \\
\hline
\end{tabular}

Adjusted: age, gender, BMI, SBP, hypertension, diabetes, PAD, $\mathrm{CHD}$, osteoporosis, CKD, COPD, fatty liver, smoking, drinking, DBP, TC, HDL-C, TG, fasting glucose, LDL-C and diuretic use. BFP, body fat percentage; BMI, body mass index; CAVI, CardioAnkle Vascular Index; CHD, coronary heart disease; CKD, chronic kidney disease; COPD, chronic obstructive pulmonary disease; DBP, diastolic blood pressure; HDL-C, high-density lipoprotein cholesterol; LDL-C, low-density lipoprotein cholesterol; PAD, peripheral artery disease; SBP, systolic blood pressure; TC, total cholesterol; TG, triglycerides. 
Table 5 Association between BFP and CAVI in subgroups

\begin{tabular}{|llll|}
\hline Characteristic & $\begin{array}{l}\text { No. of } \\
\text { participants }\end{array}$ & Effect size $(\mathbf{9 5 \%}$ Cl) & P interaction \\
\hline Age (years) & & $0.05(0.01$ to 0.09$)$ & \\
\hline $18-48$ & 287 & 0.038 \\
\hline $49-54$ & 245 & $0.05(0.01$ to 0.09$)$ & \\
\hline $55-65$ & 319 & $0.05(0.02$ to 0.08$)$ & \\
\hline $66-95$ & 301 & $0.03(0.01$ to 0.06$)$ & \\
\hline Gender & & & 0.873 \\
\hline
\end{tabular}

\begin{tabular}{|llll} 
Female & 346 & $0.03(-0.00$ to 0.06$)$ & \\
\hline Male & 766 & $0.03(0.00$ to 0.06$)$ & \\
Hypertension & & & 0.348
\end{tabular}

$\begin{array}{llll}\text { Hypertension } & 479 & 0.02(-0.00 \text { to } 0.05) & \\ \text { No } & 633 & 0.03(0.01 \text { to } 0.06) & \\ \text { Yes } & & & 0.878 \\ \text { Diabetes } & & \end{array}$

\begin{tabular}{|c|c|c|c|}
\hline No & 707 & $0.03(0.00$ to 0.05$)$ & \\
\hline Yes & 405 & $0.03(-0.00$ to 0.06$)$ & \\
\hline PAD & & & 0.964 \\
\hline No & 262 & $0.03(-0.00$ to 0.06$)$ & \\
\hline Yes & 850 & $0.03(0.00$ to 0.05$)$ & \\
\hline $\mathrm{CHD}$ & & & 0.900 \\
\hline No & 902 & 0.03 (0.00 to 0.05$)$ & \\
\hline Yes & 210 & $0.03(-0.01$ to 0.06$)$ & \\
\hline Osteoporosis & & & 0.065 \\
\hline No & 939 & $0.03(0.01$ to 0.06$)$ & \\
\hline Yes & 173 & $0.01(-0.02$ to 0.04$)$ & \\
\hline CKD & & & 0.255 \\
\hline No & 1047 & 0.03 (0.01 to 0.06$)$ & \\
\hline Yes & 65 & $0.01(-0.04$ to 0.05$)$ & \\
\hline COPD & & & 0.908 \\
\hline No & 1073 & 0.03 (0.00 to 0.05$)$ & \\
\hline Yes & 39 & $0.03(-0.04$ to 0.09$)$ & \\
\hline Fatty liver & & & 0.121 \\
\hline No & 633 & $0.02(-0.00$ to 0.05$)$ & \\
\hline Yes & 479 & 0.04 (0.01 to 0.07 ) & \\
\hline Smoking & & & 0.240 \\
\hline No & 763 & 0.03 (0.01 to 0.06$)$ & \\
\hline Yes & 349 & $0.02(-0.02$ to 0.05$)$ & \\
\hline Drinking & & & 0.166 \\
\hline No & 804 & $0.03(0.01$ to 0.06$)$ & \\
\hline Yes & 308 & $0.01(-0.03$ to 0.05$)$ & \\
\hline BMI & & & 0.173 \\
\hline$<18.5$ & 32 & $-0.07(-0.14$ to 0.00$)$ & \\
\hline$\geq 18.5,<25$ & 602 & $-0.00(-0.03$ to 0.02$)$ & \\
\hline$\geq 25$ & 478 & $-0.00(-0.03$ to 0.02$)$ & \\
\hline Fasting glucose (tertile) & & & 0.437 \\
\hline Low & 371 & $0.02(-0.00$ to 0.05$)$ & \\
\hline Middle & 364 & 0.04 (0.01 to 0.07$)$ & \\
\hline High & 377 & $0.03(-0.00$ to 0.06$)$ & \\
\hline
\end{tabular}

Above subgroups were adjusted for age, gender, BMI, SBP, hypertension, diabetes, PAD, CHD, osteoporosis, CKD, COPD, fatty liver, smoking, drinking, DBP, TC, HDL-C, TG, fasting glucose, LDL-C and diuretic use, except for its stratified variables.

$\mathrm{BMI}$, body mass index; CHD, coronary heart disease; CKD, chronic kidney disease; COPD, chronic obstructive pulmonary disease; DBP, diastolic blood pressure; HDL-C, high-density lipoprotein cholesterol; LDL-C, low-density lipoprotein cholesterol; PAD, peripheral artery disease; SBP, systolic blood pressure; TC, total cholesterol; TG, triglycerides. was negatively correlated with baPWV. Their results are apparently contradictory. The study concluded a negative correlation between BMI and CAVI, which shares the results of some prior studies ${ }^{20}$ and echoes the 'obesity paradox $^{12} 13$ that high BMI may benefit people with cardiovascular disease.

Such paradoxical relationship between BMI and arteriosclerosis may be explained by the following two aspects: first, bapwv is susceptible to blood pressure ${ }^{14}$ which undermines the accuracy of AS evaluated by bapwv and second, BMI fails to reflect the true picture of obesity, for example, a higher BMI can be found in a strong athlete. However, BFP is a more accurate, reliable and significant indicator to assess overall obesity. ${ }^{15}$ In addition, the CAVI that is immune to blood pressure introduced in this study can better reflect systemic arteriosclerosis, thus outperforming baPWV in evaluating arteriosclerosis. ${ }^{16}$ As a result, the relationship between BFP and CAVI is taken as priority in this study and results reveal the threshold curve between them, which may be attributed to the role of adipose tissue in producing hormones and cytokines. ${ }^{22}$ Different adipose tissues secrete different factors that exert anti-AS and pro-AS effects. Physiologically, the anti-AS and pro-AS factors secreted by adipose tissue are in balance. Under such state, adiponectin inhibits macrophage autophagy ${ }^{23}$ and reduces oxidative stress caused by oxidised low-density lipoprotein and high glucose to better protect vascular endothelial cells,${ }^{24}$ leptin exacerbates endothelial cell dysfunction through the proteinase C- $\beta$ pathway ${ }^{25}$ and visfatin promotes AS by inducing phenotypic alterations in macrophage that leads to insulin resistance.$^{26}$ However, in the case of obesity, such balance is disrupted when the adipose tissue within the body increases to a certain critical value, resulting in the impairment of protective adipokines, more secretion of inflammatory adipokines and the occurrence of AS. The critical value was found to be $\mathrm{BFP}=20.6 \%$ in the study, with no difference among males and females. However, more large-scale and multicentre clinical studies are still required to provide more evidence.

In addition, BFP was found to be more weakly interacted with CAVI among people $>65$ years. Existing studies reveal that age is a contributing factor to AS. A study by $\mathrm{Di}$ et $a l^{27}$ proved the positive correlation between age and CAVI even after the correction of factors including gender, blood pressure and heart rate. Previous studies ${ }^{28}$ also made clear the positive correlation between age and bapwv. Therefore, it is speculated that the reason for the weaker interaction between BFP and CAVI among people $>65$ years may be the greater effect of age on CAVI than BFP. Meanwhile, TC, TG and LDL were found to be negatively correlated with CAVI, which was obviously unreasonable and contradicted with the results of the aforementioned studies. ${ }^{28}{ }^{29}$ This may be explained by the use of lipid-lowering drugs among participants. However, due to the limitation of retrospective study, the use of lipid-lowering drugs could not be included for analysis. 


\section{Limitations}

First, this study is a cross-sectional analysis, which is not able to infer the causal relationship between BFP and CAVI. Besides, this study did not follow the population to see the effect of changes in BFP on CAVI. We were unable to include confounding factors such as exercise, diet and lipid-lowering medication into the analysis due to the retrospective nature of the study. The gender differences in the population involved in this study were large and the effect could not be completely eliminated even after correction. Finally, this study is a single-centre study, which lacks some representativeness, and we hope that this will be supported by future multicentre studies with larger samples.

\section{CONCLUSION}

Taken together, among the Chinese population included in the study, CAVI increased by 0.05 for every $1 \%$ increase in $\mathrm{BFP}$ when $\mathrm{BFP} \geq 20.6 \%$ and by 0.03 among those $>65$ years.

Contributors Study concept and design: LH and BQ. Data collection: LH, LB, LL, YL, RW, YW, ML and YW. Data analyses: LH. Data interpretation: LH, LB and BQ. Data validation: $\mathrm{BQ}$. $\mathrm{BQ}$ is responsible for the overall content. All authors contributed to the article and approved the submitted version.

Funding This work was supported by the National Natural Science Foundation of China (Grant Nos 81571373, 81601217, 82001491), Natural Science Foundation of Hubei Province of China (Grant No. 2017CFB627), Health Commission of Hubei Province scientific research project (Grant No.WJ2021M247) and Scientific Research Fund of Wuhan Union Hospital (Grant No 2019).

Competing interests None declared.

Patient consent for publication Not applicable.

Ethics approval This study was conducted in accordance with the contents of the Declaration of Helsinki. Since this study was a retrospective anonymous study, no identifying information was included, informed consent from the patients was waived. The study was approved by the Institutional Review Board of Union Hospital, Tongji Medical College, Huazhong University of Science and Technology (UHCT20168).

Provenance and peer review Not commissioned; externally peer reviewed.

Data availability statement No data are available.

Open access This is an open access article distributed in accordance with the Creative Commons Attribution Non Commercial (CC BY-NC 4.0) license, which permits others to distribute, remix, adapt, build upon this work non-commercially, and license their derivative works on different terms, provided the original work is properly cited, appropriate credit is given, any changes made indicated, and the use is non-commercial. See: http://creativecommons.org/licenses/by-nc/4.0/.

\section{ORCID iD}

Benling Qi http://orcid.org/0000-0003-3149-5707

\section{REFERENCES}

1 Roth GA, Mensah GA, Johnson CO, et al. Global burden of cardiovascular diseases and risk factors, 1990-2019: update from the GBD 2019 study. J Am Coll Cardiol 2020;76:2982-3021.

$2 \mathrm{Ng} \mathrm{M}$, Fleming T, Robinson M, et al. Global, regional, and national prevalence of overweight and obesity in children and adults during 1980-2013: a systematic analysis for the global burden of disease study 2013. Lancet 2014;384:766-81.

3 Pan X-F, Wang L, Pan A. Epidemiology and determinants of obesity in China. Lancet Diabetes Endocrinol 2021;9:373-92.

4 Lavie CJ, McAuley PA, Church TS, et al. Obesity and cardiovascular diseases: implications regarding fitness, fatness, and severity in the obesity paradox. J Am Coll Cardiol 2014;63:1345-54.

5 Alpert MA, Omran J, Mehra A, et al. Impact of obesity and weight loss on cardiac performance and morphology in adults. Prog Cardiovasc Dis 2014;56:391-400.
6 , Afshin A, Forouzanfar MH, et al, GBD 2015 Obesity Collaborators. Health effects of overweight and obesity in 195 countries over 25 years. N Engl J Med 2017;377:13-27.

7 Piché M-E, Poirier P, Lemieux I, et al. Overview of epidemiology and contribution of obesity and body fat distribution to cardiovascular disease: an update. Prog Cardiovasc Dis 2018;61:103-13.

8 Tang B, Luo F, Zhao J, et al. Relationship between body mass index and arterial stiffness in a health assessment Chinese population. Medicine 2020;99:e18793.

9 Vianna CA, Horta BL, Gonzalez MC, et al. Association of pulse wave velocity with body fat measures at $30 \mathrm{Y}$ of age. Nutrition 2019;61:38-42.

10 Rodrigues SL, Baldo MP, Lani L, et al. Body mass index is not independently associated with increased aortic stiffness in a Brazilian population. Am J Hypertens 2012;25:1064-9.

11 Yang $\mathrm{H}$, Zhao J, Deng $\mathrm{X}$, et al. Pulse wave velocity is decreased with obesity in an elderly Chinese population. J Clin Hypertens 2019;21:1379-85.

12 Doehner W, Gerstein HC, Ried J, et al. Obesity and weight loss are inversely related to mortality and cardiovascular outcome in prediabetes and type 2 diabetes: data from the origin trial. Eur Heart J 2020;41:2668-77.

13 Jordan J, Toplak H, Grassi G, et al. Joint statement of the European association for the study of obesity and the European Society of hypertension: obesity and heart failure. $J$ Hypertens 2016;34:1678-88.

14 Chen L, Liu X, Jia L, et al. Factors associated with Brachial-Ankle pulse wave velocity in an apparently healthy Chinese population. Biomed Res Int 2020;2020:1-8.

15 Park SK, Ryoo Jae-Hong, Oh Chang-Mo, et al. Body fat percentage, obesity, and their relation to the incidental risk of hypertension. $J$ Clin Hypertens 2019;21:1496-504.

16 Saiki A, Sato Y, Watanabe R, et al. The role of a novel arterial stiffness parameter, Cardio-Ankle vascular index (CAVI), as a surrogate marker for cardiovascular diseases. J Atheroscler Thromb 2016;23:155-68.

17 Czippelova B, Turianikova Z, Krohova J, et al. Arterial Stiffness and Endothelial Function in Young Obese Patients - Vascular Resistance Matters. J Atheroscler Thromb 2019;26:1015-25.

18 Para I, Albu A, Porojan MD. Adipokines and arterial stiffness in obesity. Medicina 2021;57:653.

19 Logan JG, Kang H, Kim S, et al. Association of obesity with arterial stiffness: the multi-ethnic study of atherosclerosis (MESA). Vasc Med 2020;25:309-18.

20 Gomez-Sanchez L, Garcia-Ortiz L, Patino-Alonso MC, et al. Adiposity measures and arterial stiffness in primary care: the mark prospective observational study. BMJ Open 2017;7:e016422.

21 Tabara Y, Setoh K, Kawaguchi T, et al. Factors affecting longitudinal changes in cardio-ankle vascular index in a large general population: the Nagahama study. J Hypertens 2018;36:1147-53.

22 Holroyd EW, Sirker A, Kwok CS, et al. The Relationship of Body Mass Index to Percutaneous Coronary Intervention Outcomes: Does the Obesity Paradox Exist in Contemporary Percutaneous Coronary Intervention Cohorts? Insights From the British Cardiovascular Intervention Society Registry. JACC Cardiovasc Interv 2017;10:1283-92.

23 Li C, Wang Z, Wang C, et al. Perivascular adipose tissue-derived adiponectin inhibits collar-induced carotid atherosclerosis by promoting macrophage autophagy. PLoS One 2015;10:e0124031.

24 Achari AE, Jain SK, Adiponectin JSK. Adiponectin, a therapeutic target for obesity, diabetes, and endothelial dysfunction. Int J Mol Sci 2017;18:1321.

25 Payne GA, Borbouse L, Kumar S, et al. Epicardial perivascular adipose-derived leptin exacerbates coronary endothelial dysfunction in metabolic syndrome via a protein kinase C-beta pathway. Arterioscler Thromb Vasc Biol 2010;30:1711-7.

26 Wang P, Xu T-Y, Guan Y-F, et al. Perivascular adipose tissue-derived visfatin is a vascular smooth muscle cell growth factor: role of nicotinamide mononucleotide. Cardiovasc Res 2009;81:370-80.

27 Di lorio A, Di Blasio A, Napolitano G, et al. High fat mass, low muscle mass, and arterial stiffness in a population of free-living healthy subjects: The "al passo con la tua salute" project. Medicine 2019;98:e16172.

28 Chen C, Dai J-L. Triglyceride to high-density lipoprotein cholesterol (HDL-C) ratio and arterial stiffness in Japanese population: a secondary analysis based on a cross-sectional study. Lipids Health Dis 2018;17:130.

29 Liu Y, Zhao P, Cheng M, et al. AST to ALT ratio and arterial stiffness in non-fatty liver Japanese population:a secondary analysis based on a cross-sectional study. Lipids Health Dis 2018;17:275. 